\title{
Theoretical and experimental study on mechanical characterisation of a water drop impact on a solid surface
}

\author{
Luigi Cavazza, Adriano Guarnieri, Angelo Fabbri, Chiara Cevoli, Giovanni Molari \\ Department of Agricultural and Food Sciences, Alma Mater Studiorum, University \\ of Bologna, Italy
}

\begin{abstract}
The drop impact phenomenon can be used to study many agricultural aspects related to the rainfall, runoff and irrigation, such as the stability of aggregated and the detachment of fine particles. The aim of this study was to study experimentally and numerically the water drop impact on a solid wall. In a first phase a simple experimental apparatus and basic theoretical concepts were used to investigate the influence of the drop speed on the impact pressure. In the second section, a finite element model able to reproduce the complex phenomenon observed in the experimental phase, was developed. The pressure values obtained by experimental measurement are similar to those calculated on the base of the energy conservation principle (average percentage difference of $15.6 \%$ ). Numerical model was useful to obtain important information on pressure profile inside the drop and the impact pressure during the splash, at present hard to achieve experimentally. The model was used to estimate also an almost realistic dynamic behaviour of the spreading drop.
\end{abstract}

\section{Introduction}

The splashing phenomenon occurs when a liquid droplet impacts onto a solid or liquid surface (Liu et al., 2010). The physical mechanisms of splashing are still not completely understood, droplet impact against soil can be used to study many phenomena related to rainfall,

Correspondence: Angelo Fabbri, Department of Agricultural and Food Sciences, Alma Mater Studiorum, University of Bologna, via Fanin 50, 40127 Bologna, Italy.

E-mail: angelo.fabbri@unibo.it

Key words: Water drop; rainfall; pressure; finite element model.

Received for publication: 17 June 2015.

Accepted for publication: 22 October 2015

(C) Copyright L. Cavazza et al., 2016

Licensee PAGEPress, Italy

Journal of Agricultural Engineering 2016; XLVII:487

doi:10.4081/jae.2016.487

This article is distributed under the terms of the Creative Commons Attribution Noncommercial License (by-nc 4.0) which permits any noncommercial use, distribution, and reproduction in any medium, provided the original author(s) and source are credited. runoff, irrigation, erosion of the soil and slopes. Particularly the drop impact affects the stability of aggregated and the detachment of fine particles, influencing the reorganisation, and compaction of particles in the soil surface.

The splash process can be characterised as two sub processes: the detachment or the dislodgement of particles and the transport of these particles in random directions (Mouzai and Bouhadef, 2003).

The effect of raindrop impact on soil is commonly attributed to the drop kinetic energy, momentum, or to some combination of these. Particularly this effect can be related to the drop diameter, velocity, shape, drop force and so impact pressure (Mouzai and Bouhadef, 2001). However Liu et al. (2010) reported that the pressure field (distribution) inside the drop during impact is the key factor that produces splashing. As concerning the eroding pressure, different combinations of water drop characteristics such as mass, speed and diameter can differently affect the soil detachment.

Many types of set up were used to experimentally study the water drops impact during rainfall. These techniques have been used to better isolate the major factors that affect the soil erosion by water drops (Paige et al. 2003). The majority of laboratory rainfall simulators are made by array of needles or are based on a spinning disk, which produce pulsed rain and allow to measure over water mass-flow, velocity and pressure at the impact (Thomas and El Swaify, 1989; Hignett et al. 1995; Shrivastava and Ghanshyam, 1998). Many of cited studies were strongly focused on effects on soil, considering the water energy as the key parameter (Kinnell and Wood, 1992; Regmi and Thompson, 2000).

In recent year, progress in computing efficiency coupled with reduced costs of codes has set out the numerical simulation as a powerful tool to study many physical phenomena (Norton and Sun, 2006; Fabbri et al., 2011). Numerical simulation has been already used to study the water drop impact on a porous substrate (Kumar and Deshpande, 2006; Golpaygan et al., 2008; Reis et al., 2008), heated wall (Pasandideh-Fard et al., 2001; Nikolopoulos et al., 2009), thin liquid film (Josserand and Zalesk, 2003; Pan and Suga, 2005; Fest-Santini et al., 2012) and on a solid wall (Yarin, 2006; Eggers et al., 2010; Lan and Wang, 2014).

Numerical simulations provides a detailed information comprising not only the dynamics of the drop surface with respect to its position and form but also the temporal behaviour of entire velocity and pressure fields, with details far beyond the reach of the existing experimental measurements.

The aim of this research was to study experimentally and numerically the water drop impact on a solid wall. This activity was focused as a laboratory experience, and consequently the ideal solid wall was chosen as alternative to a porous soil. This made the results obtained with different techniques more comparable. Particularly the influence of the impact speed on the impact pressure was evaluated. The work consists in a first section on drop impact experiments carried out by using simple instrument and theoretical concepts. In the second part, a finite element model able to reproduce the complex phenomenon, which was 
observed in the experimental phase, was developed. The obtained information, like velocity or pressure field, were useful to better understand physically the investigated phenomena.

\section{Materials and methods}

\section{Experimental study}

Experimental test were carried out to measure the impact pressure (Pa) of water drops as function of the hydraulic head (m).

The experimental rainfall simulator is shown schematically in Figure 1. The sprinkler was made in plastic material and it was provided of 20 holes (diameter of $1 \mathrm{~mm}$ ) distributed over a length of $92 \mathrm{~mm}$. The sprinkler was powered by a hose connected to a Mariotte bottle that maintained a constant flow regardless of the hydraulic head. The bottle contained distilled water and it was placed to a variable hydraulic head of $0.69,0.98,1.42$ and $1.85 \mathrm{~m}$. The water falls on a plastic bar characterised by a length of $140 \mathrm{~mm}$ and a width of $5.8 \mathrm{~mm}$ and placed on twoload cell with a full scale of $10 \mathrm{~N}$ (Type: L2357 s-beam; Tekkal, Milan, Italy). The voltage signal coming from the load cells was conditioned and subsequently analysed. An acquisition frequency of $60 \mathrm{~s}^{-1}$ was used. For each considered hydraulic head, eight replicates were made. All the tests were conducted at an environmental temperature of about $20^{\circ} \mathrm{C}$.

The average experimental impact pressure $\left(p_{e x}\right)$ was calculated as following:

$p_{e x}=\frac{F_{\max }}{A_{d}}$

where $F_{\max }$ is the maximum-recorded force (N) while $A_{d}$ is the conventional drop impact area of twenty drops $\left(\mathrm{m}^{2}\right)$, calculated as 20 circles of $1 \mathrm{~mm}$ diameter.

\section{Theoretical study}

The impact pressure $(p, \mathrm{~Pa})$ can be calculated on the base of the energy conservation principle, assuming a full transfer of momentum to the transducer:

$$
p=\rho_{H 2 O} \frac{v^{2}}{2}
$$

where:

$\rho_{\text {H2O }}$ : water density $\left(1000 \mathrm{kgm}^{-3}\right)$;

$v=\sqrt{v_{h}^{2}+2 g h}:$ impact speed $\left(\mathrm{ms}^{-1}\right)$

$v_{h}=\frac{4 Q m}{\rho_{H 2 O} n \pi d^{2}}:$ jet speed at the exit holes $\left(\mathrm{ms}^{-1}\right)$;

$n$ : holes number (20); $d$ : holes diameter $(0.001 \mathrm{~m})$;
$Q m=C \sqrt{z} \quad:$ mass flow $\left(\mathrm{kgs}^{-1}\right)$

$z$ : hydraulic head $(\mathrm{m}) ; C$ : plant characteristic parameter experimentally determined $(0.007727) ; g$ : gravitational acceleration $\left(\mathrm{ms}^{-2}\right) ; h$ : fall height $(0.05 \mathrm{~m})$.

\section{Finite elements model}

A numerical model able to describe the impact of a water drop falling on a flat rigid surface, was developed by using Comsol Multiphysics 5.0 (COMSOL s.r.l., Brescia, Italy).

A water drop is assumed to have an axial symmetry about the longitudinal axis. The starting geometry was associated to a sphere with a radius of $0.5 \mathrm{~mm}$. The mesh was made by 5647 tetrahedral elements, characterised by a minimum and an average element quality of 0.6932 and 0.9635 (dimensionless quantity between 0 and 1, where 1 represents a perfectly regular element, and 0 represents a degenerated element), respectively. The mesh was refined up to a level for which the calculus improvements were not significant.

Considering water (drop) and air as two phases, a laminar two-phase flow was set. The fluid flow was governed by the following NavierStokes equation:

$$
\rho\left(\frac{\partial u}{\partial t}+u \cdot \nabla u\right)=-\nabla p+\nabla\left(\mu\left(\nabla u+\nabla u^{T}\right)\right)+\rho g+\sigma
$$

where $\rho$ is the fluid density (water: $1000 \mathrm{kgm}^{-3}$; air: $1.3 \mathrm{kgm}^{-3}$ ), $\mu$ the fluid dynamic viscosity (water: 1E-3 Pas; air: 1.93E-5 Pas), $\sigma$ the surface tension coefficient between water and air $\left(72 \mathrm{mNm}^{-1}\right), g$ gravitational acceleration $\left(9.81 \mathrm{~ms}^{-2}\right), T$ the temperature $(293 \mathrm{~K})$ and $p$ the calculated pressure $(\mathrm{Pa})$.

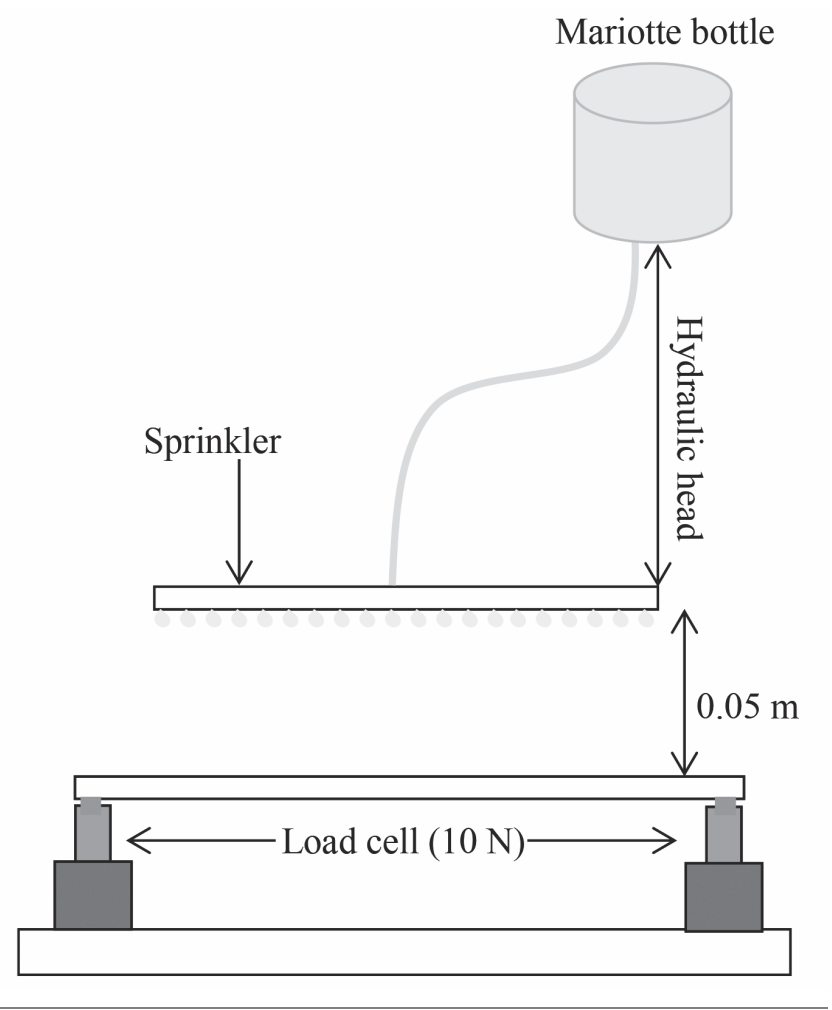

Figure 1. Experimental device. 
The initial and boundary conditions were: i) initial pressure equal to $0 \mathrm{~Pa}$, both for air and water; ii) initial speed equal to 0 and $v_{h}$ (as reported in the Equation 4), for air and water respectively; iii) the pressure on the drop boundary equal to $0 \mathrm{~Pa}$; iv) for the impact wall, a no slip boundary condition was set.

A time-dependent sparse solver named PARDISO (Parallel parse Direct Solver) was used to solve the linearized equations system, while the level-set method was used to track the interface between the gas and liquid phases. The computation was carried out on a PC with 24 CPU (Xeon5675 64 bit $3.07 \mathrm{GHz}$ ) and $24 \mathrm{~GB}$ RAM; the calculation time was about 3 hours for an impact time of $1 \mathrm{~ms}$. The results, in terms of impact pressure $(\mathrm{Pa})$, were compared with those obtained experimentally and theoretically.

\section{Results and discussion}

The experimental impact pressures as function of the hydraulic head, are reported in Figure 2. It can be seen that the pressure linearly increases with the hydraulic head with a determination coefficient of 0.982 . The pressure values range from about $337 \pm 93 \mathrm{~Pa}$ to $1096 \pm 165$ $\mathrm{Pa}$. Results obtained by theoretical study are reported in Table 1 . The jet speed at the exit holes $\left(v_{h}\right)$ increases with the hydraulic head and so also the impact pressure. The speed ranges from $0.41 \mathrm{~ms}^{-1} \quad(z=0.69$ m) to $0.67 \mathrm{~ms}^{-1}(z=1.85 \mathrm{~m})$, while impact pressure varies from $573 \mathrm{~Pa}$ to $713 \mathrm{~Pa}$. The impact speed $(v)$ values are $1.07,1.10,1.15$, and $1.19 \mathrm{~ms}^{-1}$. The percentage difference between calculated and experimental pressure values is on average $15.6 \%$, with a minimum value of $1.3 \%(z=0.98$ $\mathrm{m})$ and a maximum of $32.8 \%(z=0.69 \mathrm{~m})$.

The water drop splash was studied also by using a specific finite element model. The impact splash can be subdivided into a many phases characterised by different drop shapes. Numerical models of drop impact can be used to estimate also the detailed deformation of the spreading drop, starting from a spherical geometry. Especially, the real thickness of the lamella generated by drop impact onto a flat substrate cannot be often determined from experiments. In Figures 3 and 4, the shape evolution during the impact of a drop with a radius of $0.5 \mathrm{~mm}$ and an impact speed of $1.1 \mathrm{~ms}^{-1}$, is reported. It can be see that in the first stage of impact, the drop is strongly deformed near the bottom, while its upper part retains its original shape (1-5). Subsequently the drop starts to flatten, and deforms into a film (6-7). At the same time, the end has begun to retract, and fluid collects into a rim (8). Subsequently, retraction continues, and fluid collects into the rim, which thickens, while the film thickness remains the same (9).

The model was useful to analyse the pressure profile inside the drop and the impact pressure evolution during the splash. These measurements are impossible to carry out by experimental test. According to previous research, the pressure inside the droplet is generated during the process of impact or during the conversion of momentum of the impacting droplet into the momentum of flow along the impact surface (Liu et al., 2010).

During the first stage of impact the drop undergoes a strong deformation and the flow is redirected from a vertical to horizontal direction as a consequence of a very strong pressure gradient. This phenomenon occurs because the high-pressure region occupies a volume with the same radius as the contact area of the drop with the solid surface, similarly to the pressure distribution predicted by Hertz theory (Eggers et $a l ., 2010)$. Subsequently the high-pressure spreads over the whole drop and the vertical flow stops.

The pressure calculated at the impact point $r=0$ and $y=0$ (intersection between drop symmetry axis and the impact plane), for an impact speed of $1.1 \mathrm{~ms}^{-1}$. After the first stage, the maximum pressure decays

Table 1. Results obtained by theoretical method.

\begin{tabular}{lcccc}
$h(\mathrm{~m})$ & $Q_{m}\left(\mathrm{kgs}^{-1}\right)$ & $v_{h}\left(\mathrm{~ms}^{-1}\right)$ & $v\left(\mathrm{~ms}^{-1}\right)$ & $p(\mathrm{~Pa})$ \\
0.69 & 0.006 & 0.41 & 1.07 & 573 \\
0.98 & 0.008 & 0.49 & 1.10 & 608 \\
\hline 1.42 & 0.009 & 0.59 & 1.15 & 662 \\
1.85 & 0.011 & 0.67 & 1.19 & 713 \\
\hline
\end{tabular}

Figure 2. Experimental impact pressure as function of hydraulic

head.

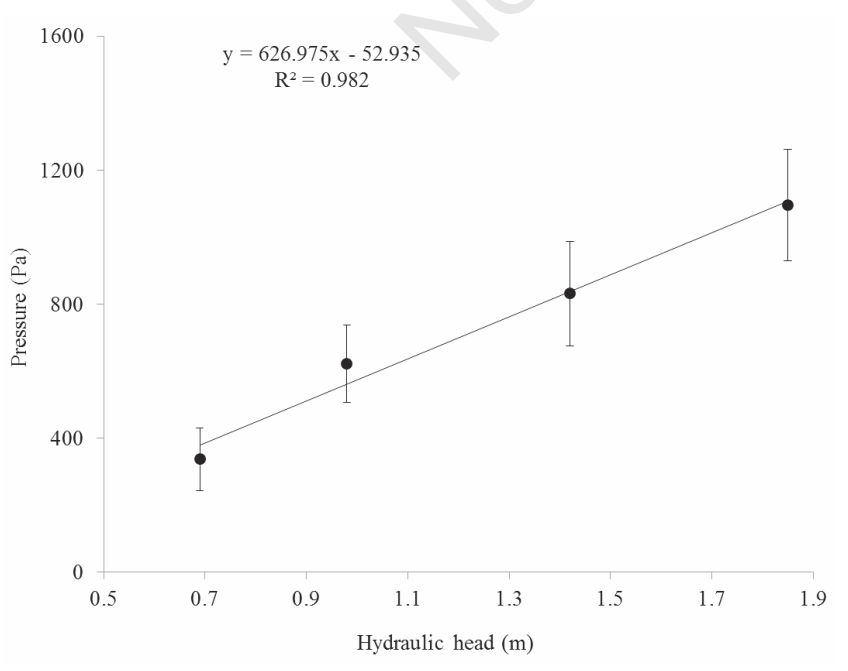

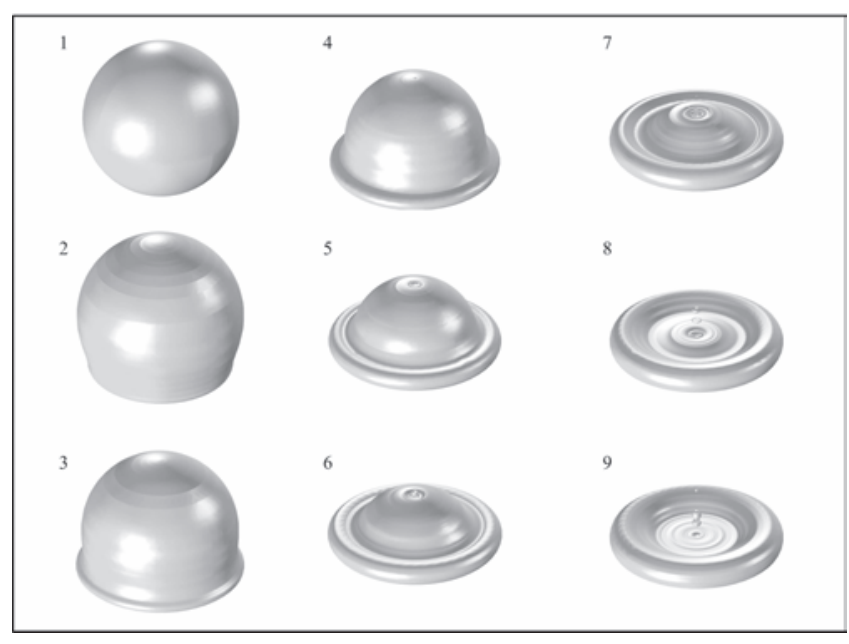

Figure 3. Change of the drop shape during the impact carried out by numerical model. 
very quickly following an exponential trend. Similarly, Eggers et al. (2010) reported that the maximum pressure in the flow decreases rapidly in a short time and that the flow in the drop is no longer pressuredriven. Accordingly, the flow in the drop was described to a good approximation by a simple hyperbolic flow with a rapidly decaying pressure.

Pressure distribution at the plane for many time values is reported in Figure 5. Particularly the pressure distribution as function of the radius, for a drop speed of $1.1 \mathrm{~m} / \mathrm{s}$ is shown. It can be see that the pressure profile reproduces the drop shape evolution reported in Figure 3. In accordance with the above, the higher-pressure values were observed near the drop centre and during the first stages of the impact.

Pressure profile of a droplet impacting at different speed (1.07, 1.10, 1.15 and $1.19 \mathrm{~ms}^{-1}$ ) are shown in Figure 6. For the smaller speed, the maximum internal pressure at moment of impact is about of $1380 \mathrm{~Pa}$. Increasing the speed, as might be expected, the pressure increases fol-

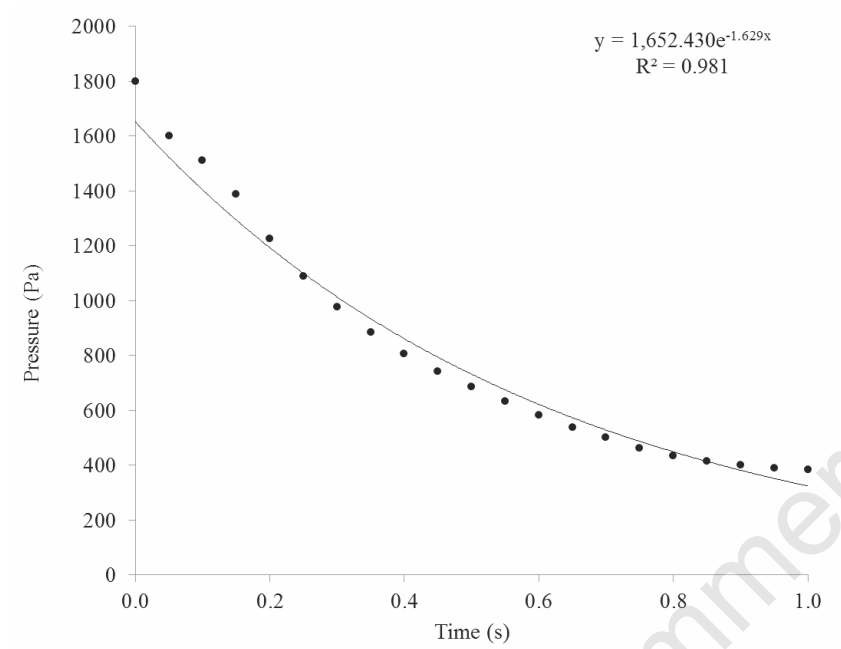

Figure 4. Pressure calculated by using the model at different impact time (impact point $r=0$ and $y=0$ and impact speed of 1.1 $\left.\mathrm{ms}^{-1}\right)$.

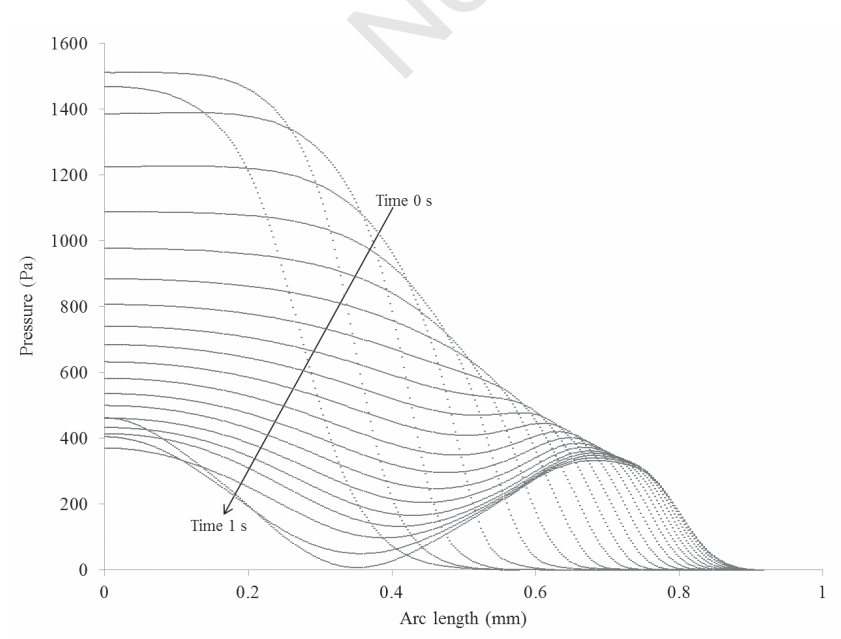

Figure 5. Pressure calculated at the plane for various instants time $\left(v=1.1 \mathrm{~ms}^{-1}\right)$. lowing approximately a power law $\left(\mathrm{R}^{2}=0.999\right)$, and it reaches a maximum values of about $1690 \mathrm{~Pa}\left(1.19 \mathrm{~ms}^{-1}\right)$ (Figure 7). By using a specific numerical model, Liu et al. (2010) reported similar results in term of the behaviour of the internal pressure; however, since the impact speed and the droplet dimensions were different, the results in terms of pressure values cannot be compared.

\section{Conclusions}

The physical phenomena involved in a drop splashing are rather complex and a unique technique for its study is actually not reported by literature. In the agricultural field, the impact drop phenomenon can be useful to study the slopes and soil erosion due to rainfall, runoff and irrigation.

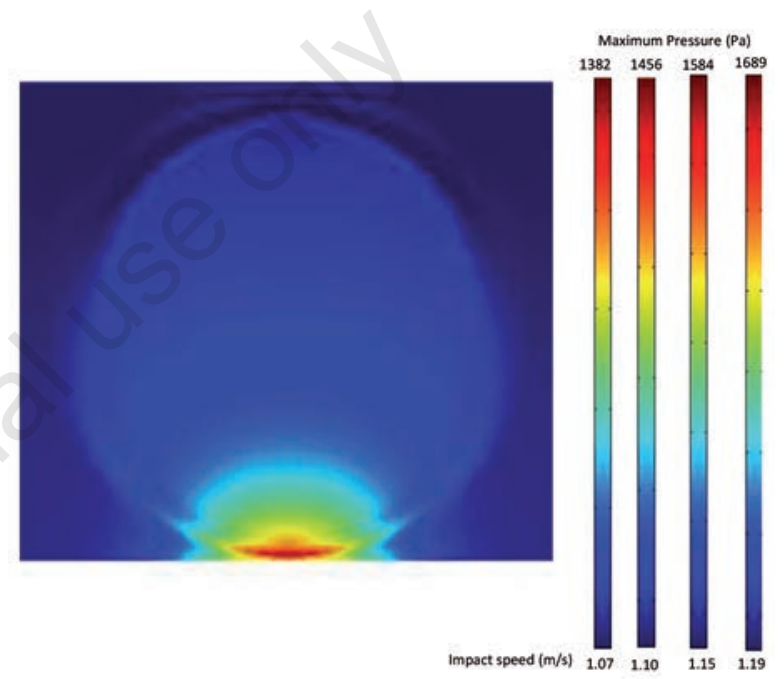

Figure 6. Pressure field calculated by using the numerical model at the impact moment for different speed.

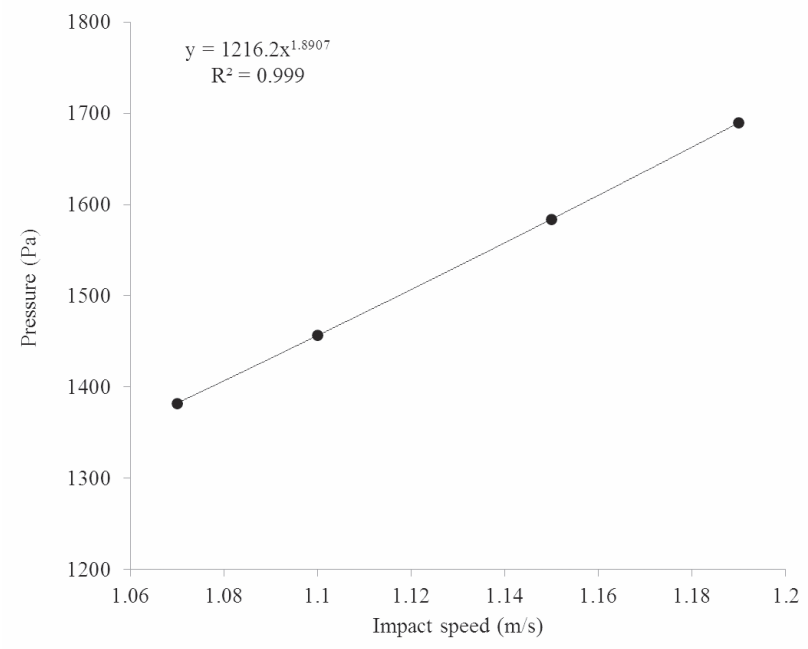

Figure 7. Maximum impact pressure calculated by using the model as function of the impact speed. 
Sensitive piezoelectric films actually available are not suited, mainly for their low resolution, and motion capture techniques does not give dynamic information. Moreover in the real world drops are not spherical, acquiring a complex shape depending from surface tension and interaction with air and gravity, often are not clearly individually separated, being instead similar to an almost irregular flow.

Nevertheless the three different approach here reported permit to gain comparable results, validating mutually in some way. As a consequence it should be possible, using the shown techniques to obtain more general results in the future, as regard different drops falling speed and diameters.

\section{References}

Eggers J., Fontelos M., Josserand C., Zalesk S. 2010. Drop dynamics after impact on a solid wall: theory and simulations. Phys. Fluids 22:062101.

Fabbri A., Cevoli C., Silaghi F.A., Guarnieri A. 2011. Numerical simulation of physical system in agri-food engineering. J. Agricult. Engine. 4:1-7.

Fest-Santini S., Guilizzoni M., Santini M., Cossali G.E. 2012. Water drop impact into a deep pool: influence of the liquid pool temperature. DIPSI Workshop on Droplet Impact Phenomena \& Spray Investigation May 18, Bergamo, Italy.

Golpaygan A., Hsu N., Ashgriz N. 2008. Numerical investigation of impact and penetration of a droplet onto a porous substrate. J. Porous Media 11:323-41.

Hignett C.T., Gusli S., Cass A., Besz, W. 1995. An automated laboratory rainfall simulation system with controlled rainfall intensity, raindrop energy and soil drainage. Soil Technol. 8:31-42.

Josserand C., Zalesk S. 2003. Droplet splashing on a thin liquid film. Phys. Fluids 15:1650-7.

Kinnell P.I.A., Wood J.T. 1992. Isolating erosivity and erodibility compo- nents in erosion by rain-impacted flow. Trans. ASAE 35:201-5.

Kumar S.M., Deshpande A.P. 2006. Dynamics of drop spreading on fibrous porous media. Colloids Surf. A Psysicochem. Engine. Aspects 277:157-63.

Lan M., Wang X. 2014. A case study on the dynamic process of water drop impacting on heated wood surface. Case Stud. Therm. Engine. $2: 23-8$.

Liu J., Vu H., Yoon S.S., Jepsen R., Aguilar G. 2010. Slashing phenomena during liquid droplet impact. Atom. Spray 20:297-300.

Mouzai L., Bouhadef M. 2003. Water drop porosity: effect on soil splash. J. Hydr. Res. 41:61-8.

Nikolopoulos N., Nikas K.S.S., Bergeles G. 2009. A numerical investigation of central binary collision of droplets. Comput. Fluids 38:1191202.

Norton T., Sun D.W. 2006. Computational fluid dynamics (CFD) e an effective and efficient design and analysis tool for the food industry: a review. Trends Food Sci. Technol. 17:600-20.

Paige G.B., Stone J.J., Smith J.R., Kennedy J.R. 2003. The walnut gulch rainfall simulator: a computer-controlled variable intensity rainfall simulator. Appl. Engine. Agric. 20:25-31.

Pan Y., Suga K. 2005. Numerical simulation of binary liquid droplet collision. Phys. Fluids 17:082105.

Pasandideh-Fard M., Aziz S.D., Chandra S., Mostaghimi J. 2001. Cooling effectivness of a water drop impinging on a hot surface. Int. J. Heat Fluid Flow 22:201-10.

Regmi T.P., Thompson A.L. 2000. Rainfall simulator for laboratory studies. Appl. Engine. Agric. 16:641-7.

Reis N.C., Griffiths R.F., Santos J.M. 2008. Parametric study of liquid droplets impinging on porous surfaces. Appl. Math. Model. 32:341-61.

Shrivastava P.K., Ghanshyam D. 1998. A review of rainfall simulators for soil erosion studies. Indian J. Soil Conserv. 26:76-80.

Thomas N.P, El Swaify S.A. 1989. Construction and calibration of a rainfall simulator. J. Agric. Engine. Res. 43:1-9.

Yarin A.L. 2006. Drop impact dynamics: splashing, spreading, receding, bouncing. Annu. Rev. Fluid Mechan. 38:159-92. 